This is an Accepted Manuscript of an article published by Taylor \& Francis in Women $\&$ Health on 08 Apr 2016, available online: https://doi.org/10.1080/03630242.2016.1160967

\title{
Gender differences in treatment progress of drug-addicted patients
}

\section{Running head: Addiction treatment progress and gender}

Javier Fernandez-Montalvo ${ }^{a}$, José J. Lopez-Goñi ${ }^{a}$, Paula Azanza ${ }^{a}$, Alfonso Arteaga ${ }^{\mathrm{a}}$ and Raul Cacho ${ }^{\mathrm{a}}$

aDepartamento de Psicología y Pedagogía

Universidad Pública de Navarra

Campus de Arrosadía s/n

31006 Pamplona

Spain

\section{Corresponding author:}

Javier Fernández-Montalvo

Departamento de Psicología y Pedagogía

Universidad Pública de Navarra

31006 Pamplona

Spain

Phone: +34948169830

E-mail: fernandez.montalvo@unavarra.es

Funding statement: This study was supported by a grant from the Health Department of the Government of Navarra, Spain (Res. 359/2012).

Acknowledgements: The authors thank the "Proyecto Hombre de Navarra" programme staff for their help in assessing the clinical sample.

Women \& Health, (2017) 57(3), 358-376, DOI: 10.1080/03630242.2016.1160967 
Title: Gender differences in treatment progress of drug-addicted patients

\begin{abstract}
This study explored the differences in treatment progress between men and women who were addicted to drugs. The differential rate of completion of/dropout from treatment in men and women with substance dependence was established. Moreover, comparisons between completers and dropouts, accounting for gender, were carried out for several variables related to treatment progress and clinical profile. A sample of 183 addicted patients (96 male and 87 female) who sought outpatient treatment between 2002 and 2006 was assessed. Information on socio-demographic, consumption and associated characteristics was collected. A detailed tracking of each patient's progress was maintained for a minimum period of eight years to assess treatment progression. The treatment dropout rate in the whole sample was 38.8\%, with statistically significant differences between women (47.1\%) and men (31.3\%). Women who dropped out of treatment presented a more severe profile in most of the psychopathologic variables than women who completed it. Moreover, women who dropped out from treatment presented a more severe profile than men who dropped out. According to these results, drug-addicted women showed worse therapeutic progress than men with similar histories. Thus, women must be provided with additional targeted intervention to promote better treatment outcomes.
\end{abstract}

Keywords: addiction; gender; assessment; treatment progress; differential profile. 


\section{Introduction}

In recent years, several studies have explored gender differences in drugaddicted patients undergoing treatment (Brady, Back, and Greenfield 2009; Greenfield et al. 2007; Walitzer and Dearing 2006). The results of these studies have shown that the profiles of men and women with substance abuse or dependence are not necessarily the same. The development of, the motivations for and the consequences of substance abuse may differ between sexes (Bravo de Medina, Echeburúa, and Aizpiri 2008; Fernández-Montalvo et al. 2014; Hser et al. 2003; Najavits and Lester 2008; Wetherington 2007).

For example, women begin using substances later than men do (Hser et al. 2003; Picci et al. 2012); however, they develop more severe addictions in terms of consequences (mainly medical, labor, economic, legal, family and social) derived from the consumption (Fernández-Montalvo et al. 2014; Green 2006; Grella, Scott, and Foss 2005) and associated psychopathologic symptoms (primarily anxiety and mood disorders) (Bravo de Medina, Echeburúa, and Aizpiri 2008; Colpaert et al. 2013; Greenfield et al. 2010; Najavits and Lester 2008; Landa et al. 2006). Moreover, women's addictions are also associated with a greater impact on their families, social life and employment (Storbjörk 2011; Walitzer and Dearing 2006). Furthermore, recent studies have shown a greater likelihood of the presence of a history of lifetime maltreatment and sexual abuse among female than male addicts attending treatment (Fernández-Montalvo, López-Goñi, and Arteaga 2015; Sacks, McKendrick, and Banks 2008). This further complicates the clinical picture that addicted women present, with more associated psychopathologic comorbidity when they seek treatment than men (Fernández-Montalvo et al. 2015). In comparison, male addicts tend to have more legal problems arising from substance consumption and a higher rate of antisocial personality 
disorder than female addicts (Hser et al. 2003; Miquel et al. 2011; Najavits and Lester 2008).

Multiple studies have examined potential gender differences in severity and course of addiction, as well as in motivation for treatment, treatment efficacy, and therapeutic outcomes, but the results have been inconsistent. While some studies have observed that women have a greater motivation for treatment, greater involvement in self-help activities and a better therapeutic outcome (Grella, Scott, and Foss 2005; López-Goñi et al. 2008; Najavits and Lester 2008), other studies have reported that gender is not directly related to treatment adherence and/or completion (Greenfield et al. 2007; Hser et al. 2003; Fernández-Montalvo et al. 2007, 2008). Furthermore, some inconsistency has been observed across studies regarding the specific relationship between gender and dropping out from treatment. While several studies have found that a significantly greater proportion of female addicts dropout, other studies have shown that male gender is a better predictor of dropping out of treatment (Brorson, et al. 2013).

These contradictory results could be related to the different types of samples used for studying dropouts (e.g., ambulatory versus residential setting), together with the different risk factors for dropout found for men and women. For example, in the Drug Abuse Treatment Outcome Study (DATOS), men were more likely to drop out of outpatient drug-free programs, whereas women were more likely to be categorized in the low-retention group for outpatient methadone treatment (Simpson et al. 1997). Gender differences in the prediction of treatment retention or dropout have been found (Brorson, et al. 2013). However, despite evidence that men and women have different experiences of treatment initiation and completion, the factors that predict these outcomes have not been reliably established. Additional studies are needed to characterize addiction treatment better in females compared to males. Elucidation of 
these differences may contribute to the future development of more effective, genderspecific treatment strategies.

Therefore, the general goal of this study was to analyze the differential treatment progress of men and women addicted to drugs (mainly alcohol and cocaine).

Specifically, the main objectives of this study were: 1) to establish the differential rate of completion and dropout of treatment in men and women with substance dependence; 2) compare completers and dropouts accounting for gender, in the number of treatment episodes, the time invested in treatment and psychopathological symptoms and 3) compare men and women, taking into account treatment completion, in the same variables mentioned above.

\section{Method}

The protocol for this study was approved by the ethics committees of the Public University of Navarre and of the "Fundación Proyecto Hombre de Navarra”. Informed consent was written and signed by all participants.

\section{Participants}

The initial sample consisted of 195 consecutive addicted patients (100 male and 95 female) who sought treatment for their addictions for the first time and entered treatment at the "Fundación Proyecto Hombre de Navarra” (Spain) between 2002 and 2006. This was $100 \%$ of patients who sought treatment for the first time during this period. Treatment was a cognitive-behavioral intervention with two different modalities (outpatient and inpatient treatment) aimed at abstinence. The main therapeutic techniques were related to stimulus control and in vivo exposure, as well as to relapse prevention. Successful program completion typically requires approximately 12 months and was achieved when a patient completed all of the therapeutic sessions. Both 
outpatient and inpatient modalities have been effective in the treatment of addictions (Fernández-Montalvo and López-Goñi 2010; Fernández-Montalvo et al. 2008).

The inclusion criteria for this study were that the patients had to: a) meet the diagnostic criteria of substance dependence according to the DSM-IV-TR (American Psychiatric Association 2000); b) be between 18 and 65 years of age; c) be receiving treatment for their addiction for the first time; d) sign informed consent to participate in the study; and e) complete two baseline assessment sessions. Following these criteria, 12 people (6.2\% of the initial sample) were excluded from the study. Therefore, the final sample was 183 participants (96 male and 87 female), 93.8\% of the initial sample.

\section{Assessment}

The European Addiction Severity Index (EuropASI; Kokkevi and Hartgers 1995) is the European version of the Addiction Severity Index (ASI; McLellan et al., 1980). This tool yields Interviewer Severity Ratings (ISR). The ISR assess the need for treatment in the following seven areas: a) general medical state (16 items), b) labor and economic situation (26 items), c) drug consumption (28 items), d) alcohol consumption (16 items), e) legal problems (23 items), f) family and social relationships (26 items), and g) psychiatric state (22 items). Severity scores range from 0 (no problem) to 9 (extreme problem) in each area, and the cut-off point indicating an additional need for treatment in each area is 4 . These areas are directly related to the severity of consumption in terms of the consequences derived from the addiction (López-Goñi et al. 2010). The Spanish version of the EuropASI was developed by Bobes et al. (1996). The ISR have been used in several studies because they offer relevant information about addiction severity (López-Goñi, Fernández-Montalvo, and Arteaga 2012). The threeday test-retest reliabilities of the ASI severity ratings have been reported to be greater than or equal to 0.92 for all domains (McLellan et al. 1985). The one-week test-retest 
reliabilities of the Spanish version used in this study ranged from 0.67 to 0.96 in the seven different areas (González et al. 2002). The alpha coefficients for the current sample were 0.70 for the ISR scores. Regarding specific scales, alpha coefficients were 0.81 (general medical scale), 0.78 (labor and economic situation), 0.80 (drug consumption), 0.86 (alcohol consumption), 0.88 (legal problems), 0.73 (family and social relationships), and 0.82 (psychiatric state).

Moreover, in this study, some items of the EuropASI were used to obtain specific information about the age at first consumption (defined as a complete consumption of a substance, e.g. a regular drink), the number of years of regular consumption (defined as a consumption with a frequency of three or more times per week or two-day binges) and the substance that motivated treatment (based on the interviewer's criteria after assessing the years of use, number of treatments and number of overdoses). The specific items of the EuropASI to assess these variables were the items 1, 2, 7, 9, and 18 of the Drug and Alcohol use scale. Furthermore, the presence of psychopathologic problems in the sample was obtained from the Psychiatric scale (items 3-10). These items are the following: Medication for psychiatric or emotional problems, severe depression, anxiety problems, cognitive problems, hallucinations, suicide ideation, problems of violence control, and suicide attempts (lifetime and past 30 days). The Cronbach's alpha for these items was 0.76 .

\section{Procedure}

Once the clinical sample was selected using the criteria described above, the baseline assessment of the sample was carried out in two sessions before beginning the treatment. All participants were interviewed by clinical psychologists who had eight or more years of experience in treating addictions and in applying the EuropASI. Sessions occurred once per week for two weeks; the time interval between sessions was the same 
for each participant (one week). In the first session, data related to socio-demographic characteristics (mainly age, gender, marital status, and employment situation) and drug consumption (mainly age at first consumption, years of consumption, substance that motivated treatment, addiction severity) were collected using the EuropASI. In the second session, the presence of psychological symptoms and problems, as well as data related to previous treatment, was assessed. After the assessment sessions, patients began the standard treatment of "Proyecto Hombre" for addiction.

To establish the EuropASI scores, the procedure used was the two-step methodology suggested by Bobes et al. (2008). First, the ratings of the seven areas of assessment were calculated based on the interviewer's judgement derived from the patient's answers, and yielded a score ranging from 0 (no problem) to 9 (extreme problems) in each area. Second, after concluding the interview, the intervention team, blind to the participant's identity, validated the interviewer's scores reviewing the answers of each patient. If a discrepancy was observed, the intervention team reappraised the patient's answers to reach an agreement.

Detailed tracking of each patient's progress was maintained to assess whether the patient completed the treatment by obtaining a therapeutic discharge or whether the patient dropped out of the treatment before the conclusion of the program (i.e., abandoned the treatment before obtaining a therapeutic discharge). Moreover, all of the patients in the sample were tracked since the beginning of the treatment for a minimum of eight years for the purpose of assessing the number of subsequent re-entries into the addiction treatment program.

\section{Data Analyses}

Descriptive analyses were conducted for all variables. Bivariate analyses were employed using $\chi^{2}$ or t-test statistics, depending on the nature of the variables studied, 
as well as Pearson's correlations. Statistical tests (alpha $=0.05$ considered statistically significant) for all of the analyses were provided. Standardized effect size (Cohen’s d) and statistical significance for all of the analyses were provided. Moreover, four discriminant analyses were carried out to determine which of the variables related to number and duration of treatment episodes were associated with gender and treatment completion. Additionally, six multiple logistic regression analyses (using the forward method) were conducted to determine the psychopathologic variables related to gender (3 models) and to treatment completion (3 models). All psychopathologic symptoms from the EuropASI (lifetime and past 30 days) were included in the models. The variable entry criterion was set to 0.05 and the variable retention criterion to 0.10 . The Hosmer-Lemeshow test was used to assess the goodness of fit of these models. A difference of $p<0.05$ was considered significant. Statistical analyses were carried out using SPSS (version 15.0 for Windows) and G*Power 3 (Faul et al. 2007).

\section{Results}

\section{Socio-demographic and Consumption Characteristics at Baseline}

The mean age of the individuals included in the study was 36.4 years $(S D=9.9$ years), and mean age did not differ significantly between men and women; the sample included 96 (52.4\%) men and 87 (47.6\%) women (Table 1). A majority of the participants were unmarried ( $\mathrm{n}=102 ; 55.7 \%$ ), without significant differences in marital status between men and women. The rate of unemployment was significantly higher in women (19.5\%) than in men (2.1\%). The main substances that motivated treatment were alcohol ( $n=84 ; 45.9 \%)$ and cocaine $(n=72 ; 39.3 \%)$, followed by other substances (e.g., heroin, cannabis, amphetamine, etc.) in smaller numbers ( $\mathrm{n}=27$; 14.7\%), with no significant differences in this variable between men and women.

\section{INSERT TABLE 1}

Women \& Health, (2017) 57(3), 358-376, DOI: 10.1080/03630242.2016.1160967 
Unadjusted comparison of consumption characteristics showed a longer time of alcohol consumption in men than in women (Table 1). However, no significant differences were observed between men and women in the duration of consumption of cocaine and cannabis.

Regarding addiction severity, the highest scores in the EuropASI were obtained for the family/social, alcohol use, drug use and psychiatric scales with statistically significant differences between men and women. Drug-addicted men scored higher than women on the legal scale, while women showed higher scores on the scales related to medical, employment/support, family/social and psychiatric problems.

\section{Rate of Completion and Dropout from Treatment}

The rate of treatment dropout in the whole sample was $38.8 \%(n=71)$, with statistically significant differences by gender $(p=0.028)$ with more women who dropped out of the treatment $(n=41 ; 47.1 \%)$ than men $(n=30 ; 31.3 \%)$.

\section{Number of Treatment Episodes and Months in Treatment during the 8+ Year}

\section{Follow-up}

The total sample had 343 treatment episodes (number of times that they had sought treatment for their addiction, independently of the therapeutic result), with a mean of 1.9 episodes per patient. Of these episodes, $72.3 \%(n=248)$ were conducted in an outpatient basis, and $27.7 \%(\mathrm{n}=95)$ were conducted in a therapeutic community. The 96 men had a total of 181 treatment episodes, and the 87 women had 162 episodes. Comparisons between men and women in the average number of treatment episodes did not differ significantly.

Significant positive correlations were found between the number of treatment episodes and severity of the addiction (assessed by the EuropASI the first time patients sought treatment at baseline) (Table 2). 


\section{INSERT TABLE 2}

The participants spent a mean of 22.8 months ( $\mathrm{SD}=16.2$ months) in treatment (total months after summing the different episodes of treatment), without statistically significant differences between men $($ mean $=22.8$; $\mathrm{SD}=14.6)$ and women $($ mean $=$ 22.9; $\mathrm{SD}=17.8) ; \mathrm{t}=0.1(\mathrm{p}=0.18)$. Moreover, significant positive correlations between months in treatment and severity of the addiction were found (Table 2).

\section{Comparisons by Gender and Treatment Completion}

\section{INSERT TABLE 3}

The men who dropped out of treatment had a greater number of treatment episodes than the men who completed treatment (Table 3). Among women, no statistically significant differences were observed in number of treatment episodes between completers and dropouts. Further, significant differences were not found in comparisons between the men and women who dropped out of treatment or between the men and women who completed treatment.

Four discriminant analyses were then carried out to determine variables related to gender and treatment completion. The results of the step-wised discriminant analyses with the five variables studied showed that only one discriminant analysis was significant (Wilks Lambda $=0.94, p=0.018$ ): the variables related to treatment completion in men. Specifically, the number of treatment episodes (on an inpatient basis) adequately classified $69.8 \%$ of cases.

\section{Comparison in Psychopathological Variables}

Women who dropped out of treatment presented a more severe psychopathologic symptom profile in most of the variables studied than women who completed treatment (Table 4). However, men showed no significant differences in such symptom severity between completers and dropouts. 
When psychopathologic symptoms were compared between men and women, while accounting for treatment completion, women who dropped out of treatment presented a more severe profile than the men who dropped out. In the case of completers, women presented more lifetime depression than men, but fewer violence problems in the last 30 days.

\section{INSERT TABLE 4}

Next, six multiple logistic regression analyses were performed to determine which specific psychopathologic variables were most relevant in differentiating between men and women, as well as between treatment completion and dropout (Table 5). The variables for which the regression analyses were adjusted were (both lifetime and past 30 days): medication for psychiatric or emotional problems, severe depression, anxiety problems, cognitive problems, hallucinations, suicide ideation, violence control problems and suicide attempts.

\section{INSERT TABLE 5}

The therapeutic discharge in the whole sample was related to not having anxiety problems in the last 30 days and not having suicide ideation. In the case of men, no variables were significantly associated with treatment completion, and no significant differences were observed in any variable between men who dropped out the treatment program and those who completed it. However, women without anxiety problems in the last 30 days and without long-life suicide ideation had higher probabilities of treatment completion.

Patients without anxiety problems or long-life suicide ideation had more probabilities of being men. Further, completers without anxiety problems and without problems of violence control in the last 30 days were mainly men. Finally, dropouts 
without anxiety problems and without suicide ideation had higher probabilities of being men.

\section{Discussion}

This study analyzed the differential treatment progress for women and men with substance dependence. Previous studies have shown differential profiles by gender when patients with substance dependence sought treatment for the first time (Fernández-Montalvo et al. 2014; Storbjörk 2011; Walitzer and Dearing 2006). Members of each gender in our study's sample, as in other studies, presented a different profile when they were assessed at the entry of the treatment. Specifically, women had a more severe addiction severity profile. Despite these differences, little is known about how different the progress of women and men is during the treatment for their drug addiction. This paper aimed to begin to approach this, and the results of this paper support the existence of gender differences in treatment progress of patients with a problem of addiction.

Women in this study dropped out of treatment at a higher rate than men, which is an important finding because treatment dropout has been shown to be an important predictor of relapse and worse therapeutic progress (Brorson et al. 2013; Grella et al. 1999; Fernández-Montalvo et al. 2007). This correlation is most likely related to the different situations found in women than in men when they seek treatment. For example, in recent studies of our research group (Fernández-Montalvo et al. 2014; Fernández-Montalvo et al. 2008), women seemed to be more reluctant to seek treatment, and when they decided to seek out consultation about their addiction problems, they were in a more severe situation and with a higher impact in the main areas of life. These results highlight the need for the development of specific strategies to make treatment more accessible to women and to include more accurate therapeutic 
techniques to avoid women’s disproportionately higher dropout rate. Therefore, therapists should attend to the specific comorbidities (anxiety, depression, suicidal ideation, etc.) and risk factors (medical problems, unemployment, and poor social and family support) found in women, when they tailor the clinical interventions.

We also assessed a frequent event in treatment programs for drug-addicted patients: the number of treatment episodes. A total of 343 episodes were observed, with a mean of 1.9 episodes of treatment by patient. No statistically significant differences were observed in number of treatment episodes between men and women. This high rate of treatment re-entries (number of times leaving and re-entering the treatment program) coincides with those from previous studies (Dennis et al. 2005; López-Goñi et al. 2014). In recent decades, the interest in this subtype of patients who, despite receiving treatment, alternate between periods of abstinence (or more controlled drug use) and periods of relapse and re-admission into treatment programs has increased (Dennis and Scott 2007; Hser, Longshore, and Douglas 2007). Studies conducted in this field show that re-admitted patients generally have a more severe profile than those who respond to first time treatment. In general, patients who re-enter treatment programs are older and with lower educational attainment than first-time admits; re-admitted patients also have lower job stability, more problems with the law, and more medical, psychiatric, and family problems than patients who seek treatment for the first time (Cacciola, Leggett, and Camilleri 2009; Hser et al. 1999; López-Goñi et al. 2014; Moos, Moos, and Finney 2001). The results of the present study support these findings, as the number of treatment episodes was positively correlated with the severity of the addiction in all areas assessed by the EuropASI, although with differences between men and women. While the number of treatment episodes for men was related to a greater severity in family/social, alcohol use, employment/support and psychiatric areas, the number of 
treatment episodes for women was related to legal, drug use, psychiatric and medical problems. These results highlight the importance of an accurate assessment and treatment the first time addicted patients go to treatment.

Results derived from comparisons between men and women (taking into account treatment completion) and between completers and dropouts (taking into account gender) showed important clinical repercussions for the development of different therapeutic strategies in treatment of men and women with substance dependence. For instance, men who dropped out of treatment appeared to have a higher probability of dropping out during future clinical interventions; in fact, men who dropped out of treatment actually had more treatment episodes. However, these results were not found in women. Women who dropped out of treatment showed more associated psychopathological symptoms than women who completed it, which was not observed as a difference for men. Moreover, women who dropped out of treatment had a worse psychopathological profile than men who dropped out; in fact, the most severe psychopathological profile was found in women who dropped out of treatment. These results coincide with those found in previous studies about gender and/or treatment reentry in drug-addicted patients (Cacciola, Leggett, and Camilleri 2009; FernándezMontalvo et al. 2014; Grella, Scott, and Foss 2005; Hser, Longshore, and Douglas 2007; López-Goñi et al. 2014; Storbjörk 2011).

This study has several limitations that should be considered. The first limitation was related to the evaluated sample. Our study included patients who sought treatment at a specialized center. Undoubtedly, this creates a bias that prevents us from generalizing the results to all addicted patients. Second, this was a correlational study that did not account for other potential factors related to the differences. Future studies should consider other factors that may explain why men and women differ in 
therapeutic progress. Moreover, the present study only included patients who had finished the assessment; patients who did not complete the two assessment sessions were not considered. We assume that patients who withdrew from treatment at an early stage had different profiles from those of patients analyzed in this study. On the other hand, this is an exploratory study with stepwise regression analyses. Future studies should confirm the relevance of the obtained variables with confirmatory methods. Finally, this study did not analyze the influence of the type of treatment received (inpatient or outpatient) on the differential therapeutic progression of men and women. In this study patients could have received both types of treatment as a part of their own therapeutic progression. Consequently, both types of treatment were not exclusive. Future studies should take into account the influence of the specific type of treatment on therapeutic progression. Due to these limitations, we must be cautious when attempting to generalize our results.

In any case, the data found in this study support the notion that addicted women in treatment have a profile that distinguishes them from addicted men. Moreover, treatment progress seems to differ by gender. Therefore, it is necessary to continue to study addiction with a focus on gender. These studies will allow a better understanding of the factors that increase resistance to treatment and an adaptation of existing intervention programs to meet the specific needs of men and women with substance abuse problems. 


\section{References}

American Psychiatric Association. 2000. Diagnostic and statistical manual of mental disorders (4th Ed. Rev.). Washington, D.C.: APA.

Bobes, J., M. P. González, P. A. Sáiz, and M. Bousoño. 1996. Índice europeo de severidad de la adicción: EuropASI. Versión española [European Index of the Addiction Severity Index: EuropASI. Spanish version]. Paper read at Actas de la IV Reunión Interregional de Psiquiatría.

Brady, K.T., S.E. Back, and S. Greenfield. 2009. Women and addiction: A comprehensive handbook. New York: Guilford Press.

Bravo de Medina, R., E. Echeburúa, and J. Aizpiri. 2008. Diferencias de sexo en la dependencia del alcohol: Dimensiones de personalidad, características psicopatológicas y trastornos de personalidad [Gender differences in alcohol dependence: Personality variables, psychopathological profile and personality disorders]. Psicothema 20 (2):218-223.

Brorson, H.H., E. Arnevic, K. Rand-Hendriksen, and F. Duckert. 2013. Drop-out from addiction treatment: A systematic review of risk factors. Clinical Psychology Review 33:1010-1024.

Cacciola, J. S., K. Leggett, and A. C. Camilleri. 2009. Treatment history: Relationship to treatment outcomes. Substance Use \& Misuse 44:305-321.

Colpaert, K., J. De Maeyer, E. Broekaert, and W. Vanderplasschen. 2013. Impact of addictions severity and psychiatric comorbidity on the quality of life of alcoholdrug- and dual-dependent persons in residential treatment. European Addiction Research 19:173-183.

Dennis, M. L., and C. K. Scott. 2007. Managing addiction as a chronic condition. Addiction Science \& Clinical Practice 4 (1):45-55. Women \& Health, (2017) 57(3), 358-376, DOI: 10.1080/03630242.2016.1160967 
Dennis, M. L., C. K. Scott, R. Funk, and M. A. Foss. 2005. The duration and correlates of addiction and treatment careers. Journal of Substance Abuse Treatment 28:S51-S62.

Faul, F., E. Erdfelder, A. G. Lang, and A. Buchner, A. 2007. G*Power 3: A flexible statistical power analysis program for the social, behavioral, and biomedical sciences. Behavior Research Methods 39: 175-191.

Fernández-Montalvo, J., J. J. López-Goñi, C. Illescas, N. Landa, and I. Lorea. 2007. Relapse precipitants in addictions: Results in a therapeutic community. Journal of Addictive Diseases 26:55-61.

Repeated Author. 2008. Evaluation of a therapeutic community treatment program: A long-term follow-up study in Spain. Substance Use \& Misuse 43 (10):13621377.

Fernández-Montalvo, J., and J.J. López-Goñi. 2010. Comparison of completers and dropouts in psychological treatment for cocaine addiction. Addiction Research \& Theory 18 (4):433-441.

Fernández-Montalvo, J., J.J. López-Goñi, and A. Arteaga. 2015. Psychological, physical and sexual abuse in addicted patients who undergo treatment. Journal of Interpersonal Violence 30 (8):1279-1298.

Fernández-Montalvo, J., J.J. López-Goñi, P. Azanza, and R. Cacho. 2014. Gender differences in drug-addicted patients in a clinical treatment center of Spain. The American Journal on Addictions 23 (4):399-406.

González, F., L. Salvador, J. M. Martínez, A. López, I. Ruz, and D. Guerra. 2002. Estudio de fiabilidad y validez de la versión española de la entrevista clínica Addiction Severity Index (ASI) [Reliability and validity of the Spanish version of the Addictions Severity Index (ASI)]. In Instrumentos de evaluación en 
drogodependencias [Assessment instruments in drug-dependences], edited by I. Iraurgi and F. González. Madrid: Aula Médica.

Green, C.A. 2006. Gender and use of substance abuse treatment service. Alcohol, Research \& Health 29:55-62.

Greenfield, S.F., S.E. Back, K. Lawson, and K.T. Brady. 2010. Substance abuse in women. Psychiatric Clinics of North America 33:339-355.

Greenfield, S.F., A.J. Brooks, S.M. Gordon, C.A. Green, F. Kropp, R.K. McHugh, M. Lincoln, D. Hien, and G.M. Miele. 2007. Substance abuse treatment entry, retention and outcome in women: A review of the literature. Drug and Alcohol Dependence 86:1-21.

Grella, C.E., Y.I. Hser, V. Joshi, and M. Douglas. 1999. Patient histories, retention, and outcome models for younger and older adults in DATOS. Drug and Alcohol Dependence 57 (2):151-166.

Grella, C.E., C.K. Scott, and M.A. Foss. 2005. Gender differences in long-term drug treatment outcomes in Chicago PETS. Journal of Substance Abuse Treatment 28:S3-S12.

Hser, Y., C.E. Grella, S. Hsieh, and M. Douglas. 1999. Prior treatment experiences related to process and outcome in DATOS. Drug and Alcohol Dependence $57: 137-150$

Hser, Y., D. Longshore, and M. Douglas. 2007. The life course perspective on drug use. A conceptual framework for understanding drug use trajectories. Evaluation Review 31:515-547.

Hser, Y.I., D. Huang, C. Teruya, and M. Douglas. 2003. Gender comparisons of drug abuse treatment outcomes and predictors. Drug and Alcohol Dependence $72: 255-264$

Women \& Health, (2017) 57(3), 358-376, DOI: 10.1080/03630242.2016.1160967 
Landa, N., J. Fernandez-Montalvo, J.J. López-Goñi, and I. Lorea. 2006. Comorbilidad psicopatológica en el alcoholismo: Un estudio descriptivo [Psychopathological comorbidity in alcoholism: A descriptive study]. International Journal of Clinical and Health Psychology 6 (2):253-269.

López-Goñi, J.J., J. Fernández-Montalvo, and A. Arteaga. 2012. Predictive validity of the EuropAsi: Clinical diagnosis or composite scoring? Journal of Substance Abuse Treatment 42 (4):392-399.

López-Goñi, J.J., J. Fernández-Montalvo, R. Cacho, and A. Arteaga. 2014. Profile of addicted patients who re-enter treatment programs. Substance Abuse 35:176183.

López-Goñi, J.J., J. Fernández-Montalvo, C. Illescas, N. Landa, and I. Lorea. 2008. Determining socio-demographic predictors of treatment dropout: Results in a therapeutic community. International Journal of Social Welfare 17 (4):374-378.

López-Goñi, J.J., J. Fernández-Montalvo, J.C. Menéndez, F. Yudego, A.R. García, and S. Esarte. 2010. Group and individual change in the treatment of drug addictions: A follow-up study in therapeutic communities. Spanish Journal of Psychology 13 (2):906-913.

McLellan, A. T., L. Luborsky, J. Cacciola, J. Griffith, F. Evans, H. L. Barr, and C. P. O’Brien. 1985. New data from the Addiction Severity Index. Reliability and validity in three centers. The Journal of Nervous and Mental Disease 173 (7): 412-423.

Miquel, L., C. Roncero, C. López-Ortiz, and M. Casas. 2011. Diferencias de género epidemiológicas y diagnósticas según eje I en pacientes con patología dual [Epidemiological and diagnostic axis I gender differences in dual diagnosis patients]. Adicciones 23 (2):165-172. 
Moos, R. H., B. S. Moos, and J. W. Finney. 2001. Predictors of deterioration among patients with substance-use disorders. Journal of Clinical Psychology 57 (12):1403-1419.

Najavits, L.M., and K.M. Lester. 2008. Gender differences in cocaine dependence. Drug and Alcohol Dependence 97:190-194.

Picci, R.L., F. Vigna-Taglianti, F. Oliva, F. Mathis, S. Salmaso, L. Ostacoli, A. Jaretti, and P. Furlan. 2012. Personality disorders among patients accessing alcohol detoxification treatment: Prevalence and gender differences. Comprehensive Psychiatry 53:355-363.

Sacks, J.Y., K. McKendrick, and S. Banks. 2008. The impact of early trauma and abuse on residential substance abuse treatment outcomes for women. Journal of Substance Abuse Treatment 34:90-100.

Simpson, D. D., G. W. Joe, K. M. Broome, M. L. Hiller, K. Knight, and G. A. RowanSzal. 1997. Program diversity and treatment retention rates in the Drug Abuse Treatment Outcome Study (DATOS). Psychology of Addictive Behaviors (11):279-293.

Storbjörk, J. 2011. Gender differences in substance use, problems, social situation and treatment experiences among clients entering adiction treatment in Stockholm. Nordic Studies on Alcohol and Drugs 28:185-209.

Walitzer, K.S., and R.L. Dearing. 2006. Gender differences in alcohol and substance use relapse. Clinical Psychology Review 26:126-148.

Wetherington, C.L. 2007. Sex-gender differences in drug abuse: A shift in the burden of proof. Experimental and Clinical Psychopharmacology 15 (5):411-417. 
Table 1. Socio-demographic and consumption characteristics of the sample at baseline by gender

\begin{tabular}{|c|c|c|c|c|c|c|c|c|c|c|}
\hline & \multicolumn{2}{|c|}{$\begin{array}{c}\text { Total } \\
(\mathrm{N}=183)\end{array}$} & \multicolumn{2}{|c|}{$\begin{array}{l}\text { Females } \\
(\mathbf{n}=\mathbf{8 7})\end{array}$} & \multicolumn{2}{|c|}{$\begin{array}{l}\text { Males } \\
(\mathrm{n}=96)\end{array}$} & \multirow[t]{2}{*}{$t$} & \multirow{2}{*}{$(d f)$} & \multirow{2}{*}{$p$} & \multirow{2}{*}{$\begin{array}{c}(1-\beta \\
\text { err. } \\
\text { Prob. })\end{array}$} \\
\hline & Mean & $( \pm \mathrm{SD})$ & Mean & $( \pm \mathrm{SD})$ & Mean & $( \pm \mathrm{SD})$ & & & & \\
\hline Mean age, years & 36.4 & (9.9) & 35.1 & (9.1) & 37.6 & 10.5 & 1.7 & $(175)$ & .102 & .73 \\
\hline \multicolumn{11}{|l|}{ Age, years, at first consumption } \\
\hline Alcohol & 17.6 & $(4.8)$ & 17.9 & $(4.8)$ & 17.5 & (4.7) & 0.5 & (162) & 0.583 & 0.14 \\
\hline Alcohol to intoxication & 24.2 & (7.9) & 27 & (8.0) & 21.8 & (7.1) & 4.2 & (141) & $p<0.001$ & 0.99 \\
\hline Cocaine & 23.0 & (6.1) & 22.3 & (5.4) & 23.4 & (6.4) & 0.9 & (117) & 0.351 & 0.24 \\
\hline Cannabis & 16.9 & $(3.8)$ & 17.5 & $(4.9)$ & 16.3 & $(2.5)$ & 1.3 & $(54.5)$ & 0.192 & 0.41 \\
\hline \multicolumn{11}{|l|}{$\begin{array}{l}\text { Years of consumption } \\
\end{array}$} \\
\hline Alcohol & 14.7 & (10.6) & 12.7 & (9.5) & 16.3 & $(11.0)$ & 2.2 & (157) & 0.031 & 0.69 \\
\hline Alcohol to intoxication & 10.7 & $(9.6)$ & 8.5 & (7.4) & 12.3 & (10.5) & 2.5 & $(136.0)$ & 0.015 & 0.75 \\
\hline Cocaine & 5.6 & (5.3) & 6.5 & $(6.0)$ & 5.4 & (4.8) & 1.1 & $(108)$ & 0.280 & 0.28 \\
\hline Cannabis & 10.1 & (7.4) & 9.7 & (7.7) & 10.6 & (7.1) & 0.6 & (81) & 0.575 & 0.14 \\
\hline \multicolumn{11}{|l|}{ Addiction severity (ISR) } \\
\hline Medical & 2.1 & (1.6) & 2.4 & (1.8) & 1.8 & (1.3) & 2.8 & (153.6) & 0.006 & 0.78 \\
\hline Employment/Support & 2.6 & (1.9) & 3.1 & $(2.0)$ & 2.1 & (1.6) & 3.7 & (163.2) & $p<0.001$ & 0.98 \\
\hline Legal & 1.5 & (1.4) & 1.2 & (1.3) & 1.7 & (1.5) & 2.4 & $(174.7)$ & 0.016 & 0.73 \\
\hline Family/Social & 4.0 & (1.8) & 4.6 & (1.7) & 3.6 & (1.7) & 3.8 & $(177)$ & $p<0.001$ & 0.98 \\
\hline Psychiatric & 3.5 & (1.9) & 4.1 & (1.7) & 2.9 & (1.8) & 4.6 & (177) & $p<0.001$ & 0.99 \\
\hline Alcohol use & 3.8 & $(2.2)$ & 3.6 & $(2.2)$ & 3.9 & (2.1) & 1.0 & (177) & 0.309 & 0.26 \\
\hline \multirow[t]{2}{*}{ Drugs use } & 3.5 & $(2.2)$ & 3.5 & (2.3) & 3.4 & (2.1) & 0.3 & (176) & 0.772 & 0.17 \\
\hline & $\mathbf{N}$ & $(\%)$ & $\mathbf{n}$ & $(\%)$ & $\mathbf{n}$ & (\%) & $X^{2}$ & $(d f)$ & & $\begin{array}{c}(1-\beta \\
\text { err. } \\
\text { Prob. })\end{array}$ \\
\hline \multicolumn{11}{|l|}{ Marital status } \\
\hline Single & 102 & $(55.7 \%)$ & 46 & $(53.0 \%)$ & 56 & (58.3\%) & & & & \\
\hline Married & 49 & (26.8\%) & 27 & (31.0\%) & 22 & (22.9\%) & 1.5 & (2) & 0.460 & 0.13 \\
\hline Divorced & 32 & (17.5\%) & 14 & $(16.0)$ & 18 & (18.7\%) & & & & \\
\hline \multicolumn{11}{|l|}{ Employment situation } \\
\hline Employed & 155 & $(84.7 \%)$ & 63 & $(72.4 \%)$ & 92 & (95.8\%) & & & & \\
\hline Unemployed & 19 & (10.4\%) & 17 & (19.5\%) & 2 & $(2.1 \%)$ & 19.6 & (2) & $p<0.001$ & 0.99 \\
\hline Other (student, retired, etc.) & 9 & $(4.9 \%)$ & 7 & $(8.0 \%)$ & 2 & $(2.1 \%)$ & & & & \\
\hline \multicolumn{11}{|l|}{$\begin{array}{l}\text { Substance that motivated } \\
\text { treatment }\end{array}$} \\
\hline Alcohol & 84 & $(45.9 \%)$ & 42 & $(48.3 \%)$ & 42 & $(43.7 \%)$ & & & & \\
\hline Cocaine & 72 & (39.3\%) & 28 & $(31.2 \%)$ & 44 & $(45.8 \%)$ & 4.9 & (2) & 0.085 & 0.38 \\
\hline Others (heroin, cannabis, etc.) & 27 & $(14.7 \%)$ & 17 & $(19.5 \%)$ & 10 & $(10.4 \%)$ & & & & \\
\hline
\end{tabular}

ISR = Interviewer Severity Rating 
Table 2. Correlations between the number of treatment episodes during the $8+$ year follow-up and severity of the addiction at baseline by gender

\begin{tabular}{lcccccc}
\hline & \multicolumn{2}{c}{ Number of treatment episodes } & \multicolumn{2}{c}{ Total months in treatment } \\
\hline \multirow{2}{*}{ EuropASI (ISR) } & Total & Female & Male & Total & Female & Male \\
& $(\boldsymbol{p})$ & $(\boldsymbol{p})$ & $(\boldsymbol{p})$ & $(\boldsymbol{p})$ & $(\boldsymbol{p})$ & $(\boldsymbol{p})$ \\
\hline \multirow{2}{*}{ Medical } & 0.197 & 0.284 & 0.066 & 0.213 & 0.254 & 0.137 \\
& $(0.008)$ & $(0.006)$ & $(0.517)$ & $(0.004)$ & $(0.014)$ & $(0.175)$ \\
\hline \multirow{2}{*}{ Employment/Support } & 0.229 & 0.12 & 0.335 & 0.101 & 0.026 & 0.213 \\
& $(0.002)$ & $(0.251)$ & $(0.001)$ & $(0.178)$ & $(0.803)$ & $(0.034)$ \\
\hline \multirow{2}{*}{ Legal } & 0.190 & 0.337 & 0.076 & 0.085 & 0.047 & 0.097 \\
& $(0.011)$ & $(0.001)$ & $(0.459)$ & $(0.262)$ & $(0.657)$ & $(0.341)$ \\
\hline \multirow{2}{*}{ Family/Social } & 0.429 & 0.253 & 0.545 & 0.302 & 0.143 & 0.452 \\
& $(p<0.001)$ & $(0.016)$ & $(p<0.001)$ & $(p<0.001)$ & $(0.176)$ & $(p<0.001)$ \\
\hline \multirow{2}{*}{ Psychiatric } & 0.305 & 0.305 & 0.303 & 0.175 & 0.085 & 0.253 \\
& $(p<0.001)$ & $(0.003)$ & $(0.002)$ & $(0.019)$ & $(0.420)$ & $(0.012)$ \\
\hline \multirow{2}{*}{ Alcohol use } & 0.301 & 0.257 & 0.383 & 0.336 & 0.353 & 0.331 \\
& $(p<0.001)$ & $(0.014)$ & $(p<0.001)$ & $(p<0.001)$ & $(0.001)$ & $(0.001)$ \\
\hline \multirow{2}{*}{ Drugs use } & 0.225 & 0.337 & 0.137 & -0.037 & -0.1 & 0.058 \\
& $(0.003)$ & $(0.001)$ & $(0.175)$ & 0.624 & $(0.219)$ & $(0.567)$ \\
\hline
\end{tabular}

ISR = Interviewer Severity Rating 
Table 3. Comparisons in treatment episodes and months in treatment by gender

\begin{tabular}{|c|c|c|c|c|c|c|c|c|c|c|c|c|c|c|}
\hline & \multicolumn{14}{|c|}{ GENDER } \\
\hline & \multicolumn{7}{|c|}{$\begin{array}{l}\text { Female } \\
(\mathrm{n}=87)\end{array}$} & \multicolumn{7}{|c|}{$\begin{array}{c}\text { Male } \\
(n=96)\end{array}$} \\
\hline & \multicolumn{2}{|c|}{$\begin{array}{c}\text { Dropouts } \\
(\mathrm{n}=41)\end{array}$} & \multicolumn{2}{|c|}{$\begin{array}{l}\text { Completers } \\
\quad(n=46)\end{array}$} & \multirow[t]{2}{*}{$t(d f)$} & \multirow[t]{2}{*}{$p$} & \multirow[t]{2}{*}{ (1 - B err. Prob.) } & \multicolumn{2}{|c|}{$\begin{array}{c}\text { Dropouts } \\
(n=30)\end{array}$} & \multicolumn{2}{|c|}{$\begin{array}{l}\text { Completers } \\
\quad(n=66)\end{array}$} & \multirow[t]{2}{*}{$t(d f)$} & \multirow[t]{2}{*}{$p$} & \multirow[t]{2}{*}{ (1 - $\beta$ err. Prob.) } \\
\hline & Mean & $( \pm \mathrm{SD})$ & Mean & $( \pm \mathrm{SD})$ & & & & Mean & $( \pm \mathrm{SD})$ & Mean & $( \pm \mathrm{SD})$ & & & \\
\hline TE (outpatient) & 1.4 & $(0.9)$ & 1.1 & $(0.6)$ & $1.5(64.9)$ & 0.133 & 0.44 & 1.8 & $(1.1)$ & 1.3 & $(0.8)$ & $2.1(43.6)$ & 0.039 & 0.75 \\
\hline TE (inpatient) & 0.7 & $(1.0)$ & 0.5 & $(1.1)$ & $0.6(85)$ & 0.539 & 0.25 & 0.6 & $(1.2)$ & 0.3 & $(0.6)$ & $1.2(37.0)$ & 0.225 & 0.44 \\
\hline TE (total) & 2.1 & (1.3) & 1.7 & (1.5) & $1.3(85)$ & 0.186 & 0.37 & 2.4 & $(1.8)$ & 1.6 & $(1.2)$ & $2.1(40.1)$ & 0.046 & 0.75 \\
\hline MT (maximum) & 14.5 & $(11.8)$ & 19.5 & $(12.3)$ & $1.9(85)$ & 0.055 & 0.60 & 18.7 & (11.9) & 16.6 & $(8.5)$ & $0.8(42.9)$ & 0.400 & 0.25 \\
\hline \multirow[t]{5}{*}{ MT (total) } & 20.1 & $(15.3)$ & 25.4 & $(19.7)$ & $1.4(85)$ & 0.161 & 0.40 & 26.1 & $(17.1)$ & 21.1 & $(13.5)$ & $1.4(46.1)$ & 0.171 & 0.45 \\
\hline & \multicolumn{14}{|c|}{ TREATMENT COMPLETION } \\
\hline & \multicolumn{7}{|c|}{$\begin{array}{c}\text { Dropouts } \\
(\mathrm{n}=71)\end{array}$} & \multicolumn{7}{|c|}{$\begin{array}{c}\text { Completers } \\
(\mathrm{n}=112)\end{array}$} \\
\hline & \multicolumn{2}{|c|}{$\begin{array}{l}\text { Female } \\
(n=41)\end{array}$} & \multicolumn{2}{|c|}{$\begin{array}{c}\text { Male } \\
(\mathrm{n}=\mathbf{3 0})\end{array}$} & \multirow[t]{2}{*}{$t(d f)$} & \multirow[t]{2}{*}{$p$} & \multirow[t]{2}{*}{$(1-\beta$ err. Prob. $)$} & \multicolumn{2}{|c|}{$\begin{array}{l}\text { Female } \\
(n=46)\end{array}$} & \multicolumn{2}{|c|}{$\begin{array}{c}\text { Male } \\
(n=66)\end{array}$} & \multirow[t]{2}{*}{$t(d f)$} & \multirow[t]{2}{*}{$p$} & \multirow[t]{2}{*}{$(1-\beta$ err. Prob. $)$} \\
\hline & Mean & (土SD) & Mean & $( \pm \mathrm{SD})$ & & & & Mean & $( \pm \mathrm{SD})$ & Mean & $( \pm \mathrm{SD})$ & & & \\
\hline TE (outpatient) & 1.4 & $(0.9)$ & 1.8 & $(1.1)$ & $1.6(69)$ & 0.122 & 0.45 & 1.1 & 0.6 & 1.3 & 0.8 & $1.3(110)$ & 0.207 & 0.35 \\
\hline TE (inpatient) & 0.7 & $(1.0)$ & 0.6 & $(1.2)$ & $0.2(69)$ & 0.848 & 0.07 & 0.5 & 1.1 & 0.3 & 0.6 & $1.1(66.1)$ & 0.287 & 0.31 \\
\hline TE (total) & 2.1 & $(1.3)$ & 2.4 & $(1.8)$ & $0.9(69)$ & 0.381 & 0.22 & 1.7 & 1.5 & 1.7 & 1.2 & $0.1(110)$ & 0.929 & 0.06 \\
\hline MT (maximum) & 14.5 & (11.9) & 18.7 & (11.9) & 1.5 (69) & 0.145 & 0.42 & 19.5 & 12.3 & 16.6 & 8.5 & $1.4(74.0)$ & 0.170 & 0.43 \\
\hline MT (total) & 20.1 & (15.3) & 26.1 & $(17.1)$ & $1.6(69)$ & 0.124 & 0.66 & 25.4 & 19.7 & 21.1 & 13.5 & $1.4(110)$ & 0.173 & 0.39 \\
\hline
\end{tabular}

TE = Treatment episodes; MT (maximum) = Months in treatment during the longest episode; MT (total) $=$ Total sum of months in treatment 
Table 4. Comparisons in psychopathologic variables (lifetime and past 30 days) by gender

\begin{tabular}{|c|c|c|c|c|c|c|c|c|c|c|}
\hline \multirow[b]{3}{*}{$\begin{array}{l}\text { Psychopathologic } \\
\text { symptoms }\end{array}$} & \multicolumn{10}{|c|}{ GENDER } \\
\hline & \multicolumn{5}{|c|}{$\begin{array}{l}\text { Female } \\
(\mathbf{n}=87)\end{array}$} & \multicolumn{5}{|c|}{$\begin{array}{c}\text { Male } \\
(\mathrm{n}=96)\end{array}$} \\
\hline & $\begin{array}{c}\text { Dropouts } \\
(\mathrm{n}=41)\end{array}$ & $\begin{array}{c}\text { Completers } \\
(n=46)\end{array}$ & \multirow{2}{*}{$\begin{array}{c}X^{2} \\
(\mathbf{d f}=1)\end{array}$} & \multirow{2}{*}{$p$} & \multirow{2}{*}{$\begin{array}{c}1-\beta \text { err. } \\
\text { Prob }\end{array}$} & $\begin{array}{c}\text { Dropouts } \\
(\mathrm{n}=\mathbf{3 0})\end{array}$ & $\begin{array}{c}\text { Completers } \\
(\mathrm{n}=66)\end{array}$ & \multirow{2}{*}{$\begin{array}{c}X^{2} \\
(\mathrm{df}=1)\end{array}$} & \multirow{2}{*}{$p$} & \multirow{2}{*}{$\begin{array}{c}1-\beta \text { err. } \\
\text { Prob }\end{array}$} \\
\hline (Lifetime) & n (\%) & n (\%) & & & & n (\%) & n (\%) & & & \\
\hline $\begin{array}{l}\text { Medication for psychiatric or } \\
\text { emotional problems }\end{array}$ & $28(68.3 \%)$ & $21(45.6 \%)$ & 4.5 & 0.034 & 0.21 & $12(40 \%)$ & 30 (45.4\%) & 0.2 & 0.618 & 0.06 \\
\hline Severe depression & $35(85.4 \%)$ & $29(63.0 \%)$ & 5.5 & 0.018 & 0.47 & $16(53.3 \%)$ & 28 (42.4\%) & 1.0 & 0.320 & 0.10 \\
\hline Anxiety problems & 37 (92.5\%) & $36(78.3 \%)$ & 3.4 & 0.066 & 0.32 & $19(63.3 \%)$ & 34 (51.5\%) & 1.2 & 0.280 & 0.11 \\
\hline Cognitive problems & $20(48.8 \%)$ & $24(52.2 \%)$ & 0.0 & 0.841 & 0.05 & $8(26.7 \%)$ & 24 (36.4\%) & 0.9 & 0.350 & 0.10 \\
\hline Hallucinations & 7 (17.1\%) & $5(10.9 \%)$ & 0.6 & 0.425 & 0.07 & $2(6.7 \%)$ & 15 (22.7\%) & 3.6 & 0.056 & 0.48 \\
\hline Suicide ideation & $32(78.1 \%)$ & $21(45.6 \%)$ & 9.6 & 0.002 & 0.74 & $13(43.3 \%)$ & 19 (28.8\%) & 2.0 & 0.161 & 0.15 \\
\hline Problems of violence control & $17(43.9 \%)$ & $18(39.1 \%)$ & 0 & 0.825 & 0.05 & $11(36.7 \%)$ & $26(39.4 \%)$ & 0.1 & 0.799 & 0.05 \\
\hline Suicide attempts & $20(48.8 \%)$ & $11(23.9 \%)$ & 5.8 & 0.016 & 0.45 & $4(13.3 \%)$ & $8(12.1 \%)$ & 0.0 & 0.910 & 0.05 \\
\hline \multicolumn{11}{|l|}{ (Past 30 Days) } \\
\hline $\begin{array}{l}\text { Medication for psychiatric or } \\
\text { emotional problems }\end{array}$ & $24(58.5 \%)$ & $21(45.6 \%)$ & 1.4 & 0.230 & 0.12 & 7 (23.3\%) & 22 (33.3\%) & 1.0 & 0.323 & 0.07 \\
\hline Severe depression & $11(26.8 \%)$ & $12(26.1 \%)$ & 0 & 0.938 & 0.05 & $4(13.3 \%)$ & $12(18.2 \%)$ & 0.4 & 0.555 & 0.07 \\
\hline Anxiety problems & $24(58.5 \%)$ & $17(36.9 \%)$ & 4.6 & 0.033 & 0.34 & $9(30.0 \%)$ & 18 (27.3\%) & 0.1 & 0.783 & 0.05 \\
\hline Cognitive problems & $18(43.9 \%)$ & $15(32.6 \%)$ & 1.2 & 0.239 & 0.12 & $6(20.0 \%)$ & $21(31.8 \%)$ & 1.4 & 0.233 & 0.12 \\
\hline Hallucinations & $1(2.4 \%)$ & $2(4.3 \%)$ & 0.3 & 0.613 & 0.05 & 0 & 0 & -- & -- & -- \\
\hline Suicide ideation & $11(26.8 \%)$ & $2(4.3 \%)$ & 8.6 & 0.003 & 0.88 & $4(13.3 \%)$ & $2(3.0 \%)$ & 3.8 & 0.053 & 0.27 \\
\hline Problems of violence control & $6(14.6 \%)$ & 0 & -- & -- & -- & $1(3.3 \%)$ & $6(9.1 \%)$ & 1.0 & 0.315 & 0.15 \\
\hline \multirow[t]{3}{*}{ Suicide attempts } & $2(4.9 \%)$ & $1(2.2 \%)$ & 0.5 & 0.503 & 0.08 & $1(3.3 \%)$ & $1(1.5 \%)$ & 0.3 & 0.613 & 0.06 \\
\hline & \multicolumn{10}{|c|}{ TREATMENT COMPLETION } \\
\hline & \multicolumn{5}{|c|}{$\begin{array}{c}\text { Dropouts } \\
(\mathrm{n}=71)\end{array}$} & \multicolumn{5}{|c|}{$\begin{array}{c}\text { Completers } \\
(\mathbf{n}=112)\end{array}$} \\
\hline (Lifetime) & $\begin{array}{l}\text { Female } \\
(n=41)\end{array}$ & $\begin{array}{c}\text { Male } \\
(\mathrm{n}=30)\end{array}$ & $\begin{array}{c}X^{2} \\
(\mathrm{df}=1)\end{array}$ & $p$ & $\begin{array}{c}1-\beta \text { err. } \\
\text { Prob }\end{array}$ & $\begin{array}{l}\text { Female } \\
(n=46)\end{array}$ & $\begin{array}{c}\text { Male } \\
(\mathrm{n}=66)\end{array}$ & $\begin{array}{c}X^{2} \\
(\mathrm{df}=1)\end{array}$ & $p$ & $\begin{array}{c}1-\beta \text { err. } \\
\text { Prob }\end{array}$ \\
\hline $\begin{array}{l}\text { Medication for psychiatric or } \\
\text { emotional problems }\end{array}$ & $28(68.3 \%)$ & $12(40.0 \%)$ & 5.6 & 0.018 & 0.44 & $21(45.6 \%)$ & $30(45.4 \%)$ & 0 & 0.984 & 0.05 \\
\hline Severe depression & $35(85.4 \%)$ & $16(53.3 \%)$ & 8.8 & 0.003 & 0.67 & $29(63.0 \%)$ & 28 (42.4\%) & 4.6 & 0.032 & 0.36 \\
\hline Anxiety problems & 37 (92.5\%) & $19(63.3 \%)$ & 9.1 & 0.003 & 0.79 & $36(78.3 \%)$ & 34 (51.5\%) & 8.3 & 0.004 & 0.68 \\
\hline Cognitive problems & $20(48.8 \%)$ & $8(26.7 \%)$ & 3,9 & 0.049 & 0.31 & $24(52.2 \%)$ & $24(36.4 \%)$ & 2.8 & 0.096 & 0.22 \\
\hline Hallucinations & 7 (17.1\%) & $2(6.7 \%)$ & 1,7 & 0.193 & 0.18 & $5(10.9 \%)$ & 15 (22.7\%) & 2.4 & 0.118 & 0.22 \\
\hline Suicide ideation & $32(78.1 \%)$ & $13(43.3 \%)$ & 9.0 & 0.003 & 0.68 & $21(45.6 \%)$ & $19(28.8 \%)$ & 3.4 & 0.067 & 0.25 \\
\hline Problems of violence control & 17 (43.9\%) & $11(36.7 \%)$ & 0.2 & 0.683 & 0.06 & $18(39.1 \%)$ & $26(39.4 \%)$ & 0 & 0.978 & 0.05 \\
\hline Suicide attempts & $20(48.8 \%)$ & $4(13.3 \%)$ & 9.7 & 0.002 & 0.85 & $11(23.9 \%)$ & $8(12.1 \%)$ & 2.4 & 0.118 & 0.13 \\
\hline \multicolumn{11}{|l|}{ (Past 30 Days) } \\
\hline $\begin{array}{l}\text { Medication for psychiatric or } \\
\text { emotional problems }\end{array}$ & $24(58.5 \%)$ & 7 (23.3\%) & 8.8 & 0.003 & 0.71 & $21(45.6 \%)$ & 22 (33.3\%) & 1.7 & 0.187 & 0.14 \\
\hline Severe depression & $11(26.8 \%)$ & $4(13.3 \%)$ & 1.9 & 0.169 & 0.17 & $12(26.1 \%)$ & $12(18.2 \%)$ & 1.0 & 0.316 & 0.09 \\
\hline Anxiety problems & $24(68.5 \%)$ & $9(30.0 \%)$ & 6.2 & 0.013 & 0.48 & $17(36.9 \%)$ & $18(27.3 \%)$ & 1.2 & 0.277 & 0.10 \\
\hline Cognitive problems & $18(43.9 \%)$ & $6(20.0 \%)$ & 4.8 & 0.029 & 0.41 & $15(32.6 \%)$ & $21(31.8 \%)$ & 0 & 0.930 & 0.05 \\
\hline Hallucinations & $1(2.4 \%)$ & 0 & -- & -- & -- & $2(4.3 \%)$ & 0 & -- & -- & -- \\
\hline Suicide ideation & $11(26.8 \%)$ & $4(13.3 \%)$ & 1.9 & 0.169 & 0.17 & $2(4.3 \%)$ & $2(3.0 \%)$ & 0.1 & 0.712 & 0.05 \\
\hline Problems of violence control & $6(14.6 \%)$ & $1(3.3 \%)$ & 2.5 & 0.115 & 0.35 & 0 & $6(9.1 \%)$ & -- & -- & -- \\
\hline Suicide attempts & 2 (4.9\%) & $1(3.3 \%)$ & 0.1 & 0.749 & 0.06 & $1(2.2 \%)$ & $1(1.5 \%)$ & 0.0 & 0.837 & 0.99 \\
\hline
\end{tabular}


Table 5. Results of multivariate analysis

Logistic Regression: Psychopathological Variables

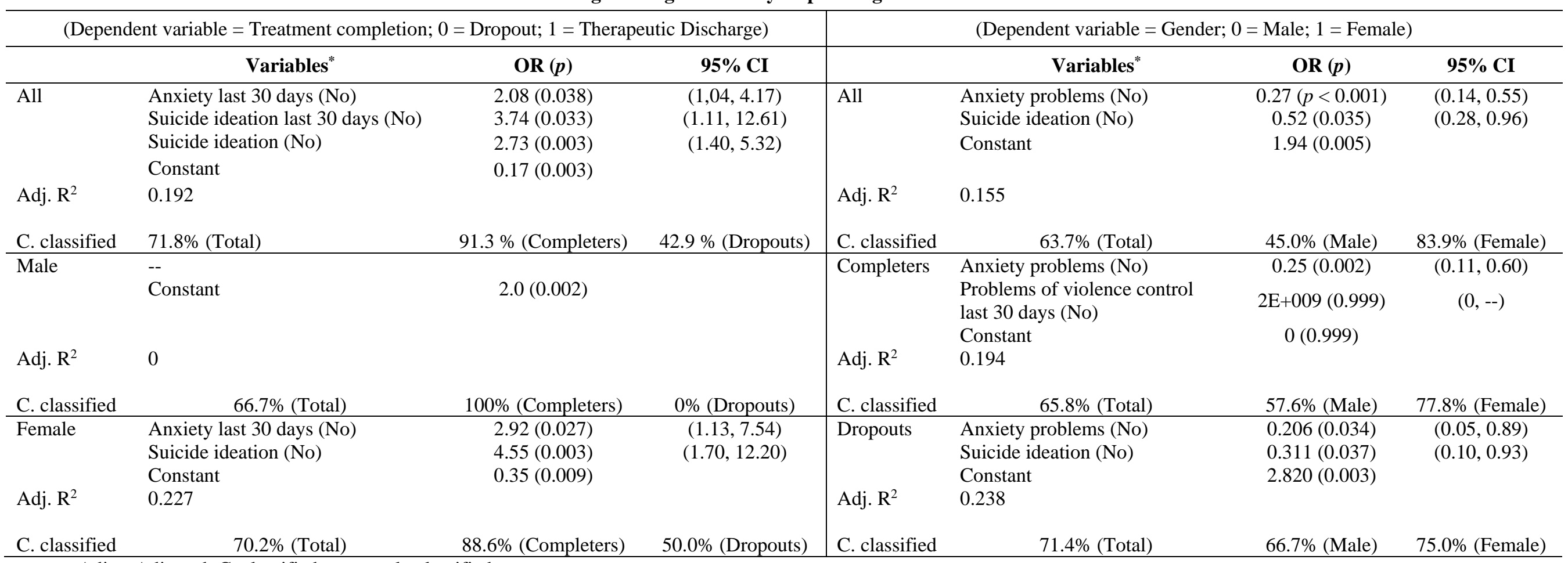

Adj. = Adjusted; C. classified $=$ correctly classified

*All psychopathological symptoms from the EuropASI (lifetime and past 30 days) were included in the models 